\title{
Study of the Incentive Caused by the Scrappage Program in Accelerating Old-Car Replacement in Order to Reduce Gas Emissions from Gasoline Passenger Cars in Indonesia
}

\author{
Abdi Pratama*, Akihiro Tokai, Kojima Naoya \\ Division of Sustainable Energy and Environmental Engineering, Graduate School of Engineering, Osaka University \\ Osaka, Japan \\ *Corresponding author's email: totemojapan [AT] yahoo.com
}

\begin{abstract}
This paper describes a scenario designed to reduce the emission level of non-europ cars that makes up more than $80 \%$ of the current car stock in 2013, even though the number of non-euro cars is only a maximum of $24 \%$ of the total population. We have applied an incentive for people to replace their non-euro car with a newer LCGC car through a scrappage program. Willingness to change was determined through a questionnaire to determine the respondent's willingness to change to an LCGC car. From the survey, the financial aspect still dominated the motivation behind the replacement. This was shown from the choice of the highest incentive fee of $\$ 2,000$ USD per unit. By applying $78 \%$ and $82 \%$ to describe the probability of changing to the LCGC car and the incentive option of $\$ 2,000$ USD respectively, it was proven that the incentive program can reduce the population of non-euro cars. From the results, it can be seen that emission gases $\mathrm{CO}, \mathrm{NO}$, and $\mathrm{HC}$ decreased significantly; $\mathrm{CO}$ by $59.3 \%$, NO by $68.1 \%$, and $\mathrm{HC}$ by $35.4 \%$ compared to without the scrappage incentive program by 2030 . Because each unit is replaced with a LCGC car, the population balance is zero. The increase of the emission level from the additional number of LCGC cars is not significant compared to the emissions from non-euro cars. We conclude that the incentive program for non-euro cars is one of the most effective ways to reduce the gas emission level.
\end{abstract}

Keywords- emission, passenger car, policy control, scrappage, Indonesia

\section{INTRODUCTION}

The growth of the use of passenger gasoline cars in Indonesia has been significantly increasing over the last decade (Gaikindo, 2015). The increase of emissions from vehicles has become a concerning issue. The negative effect on the environment has become an important reason to control emissions from vehicles, and is both necessary and urgent. This growth will contribute to the increase in gas emission levels. Several actions have been undertaken by both the stakeholders and car manufacturers to improve the performance of vehicles, such as the Low Cost Green Car (LCGC) policy (Moi, 2013). This policy enforced car manufacturers to fulfil the requirements of the policy; 20 kilometres per litre for gasoline consumption. An LCGC-categorised car can be one option to reduce the emissions from vehicles as well as being an option to replace older cars.

However, there are no specific regulations controlling the life of vehicles, such as retirement age limitations. The age of the car can be considered to be unlimited. Consequently, the car population will potentially increase year by year without any particular regulations to limit and control growth. The small portion of cars retired due to natural disasters or traffic accidents can be neglected. It becomes crucial because the emission level of each car will also increase in line with its age. Newer car will have better emission levels compared to older vehicles after a certain level of usage and travelled distance. The contribution from older cars is bigger than from newer cars over the same travel distance. Furthermore, non-euro car have multiple emissions compare to euro cars. Figure 1 shows the composition of passenger cars in 2013 based on car age (BPS, 2013). Non-euro cars dominated $24.0 \%$ of the total population of gasoline passenger cars in 2013. Non-euro cars are defined as a vehicle, which is not equipped with a catalytic converter in the exhaust pipe running from the engine. Residue gases from the combustion of the fuel and air will pass through without any compression and conversion by the catalytic converter. In previous work, Nugroho and Fujiwara (2005) calculated euro and non-euro emission levels. Non-euro cars have a multiple emissions compared to euro cars, when it comes to $\mathrm{CO}, \mathrm{HC}$, and $\mathrm{NO}$ gases. Although the portion of euro cars has increased, because new car registration was dominated by euro cars after the implementation of the euro 2 regulation since 2001 (Nugroho and Fujiwara, 2005), the biggest portion of emissions from non-euro cars cannot be neglected and will continuously exist, unless non-euro cars are forced to retire. 




Figure1: Passenger car population based on age distribution

Therefore, accelerating the retirement of older non-euro cars is one of the potential options to reduce gas emission levels. In several countries, accelerating the retirement of older vehicles through an incentive program has been tried and implemented in previous years in multiple countries. France (Yamamoto et al., 2004), Ireland (Hennessy and Richard, 2011), Germany (Böckers et al., 2012) and Greece (Nicholas, 1999) have introduced an incentive program to reduce their old fleet. The number of incentive is different for each country. There are no similar patterns or positive correlations related to the amount of the incentive. The policy is taken based on each countries' condition. The scheme of the program is also different from country to country (minimum car age, amount of incentive, replacement model etc). The scrappage payment can lead to a large, immediate reduction in emissions (BenDor and Ford, 2006).

It had been discussed that the scrappage program had a positive effect on the reduction of emissions. The scrappage program appears to be cost-effective and may be a useful component of an overall policy to reduce emissions (Alberini et al., 1996). It has been shown that while a subsidy on the initial purchase of the car brings forward an optimal replacement time, the impact of the incentive for car replacement has been proven effective in Greece when compared with two other measures offered; traffic restriction and fuel taxes aimed at reducing car use (Nicholas, 1999). Scrappage payment can also lead to a large or immediate reduction in emissions (BenDor and Ford, 2006). These positive results might be applicable to Indonesia.

The purpose of this paper is to discover the effects of the incentive scrappage program in relation to accelerating old car replacement and its effect on controlling the increase in the gas emission level in Indonesia. LCGC-categorised cars will be an option to replace retired cars. Emission level changes will be calculated to determine the effectiveness of the program. The final result will be expressed as $\mathrm{CO}, \mathrm{NO}$ and $\mathrm{HC}$ as the environmental factor. The research into this topic has been very limited. This study is an important item of leading research in this particular field of study in Indonesia.

\section{MATERIALS AND METHOD}

\section{1 Research Framework}

We constructed the research framework to contain three main parts; the incentive scrappage program, the willingness to change, and emission replacement. As described in Figure 2, we introduced the incentive scrappage program. As the scrappage program is a voluntary program, in order to get to know the willingness of the people when it comes to changing their old car, we distributed questionnaires to 120 respondents. The questionnaire's purpose was to know the willingness of the car owner to replace their car. The questionnaire was constructed by offering a replacement for their old car, a new LCGC car. We promoted the LCGC car as an environmentally-friendly car with lower emissions, retailing at an affordable price, and being of high quality.

Voluntary replacement with zero incentive and incentives of $\$ 500$ USD, $\$ 1,000$ USD, $\$ 1,500$ USD, and $\$ 2,000$ USD were offered to determine the nature of the willingness to change. We also looked into the main reason for changing their old car, such as price, quality, and the environmental aspect. In the end, to cross-check their willingness, we also confirmed their environmental awareness when driving a car. For example, the car's periodical maintenance, and their driving habit during traffic jams, loading habits etc. Willingness to change will influence the proportion of stock cars in the market, 
which will be calculated as emission replacement concerning going from the old car to the LCGC car as the replacement option offered.

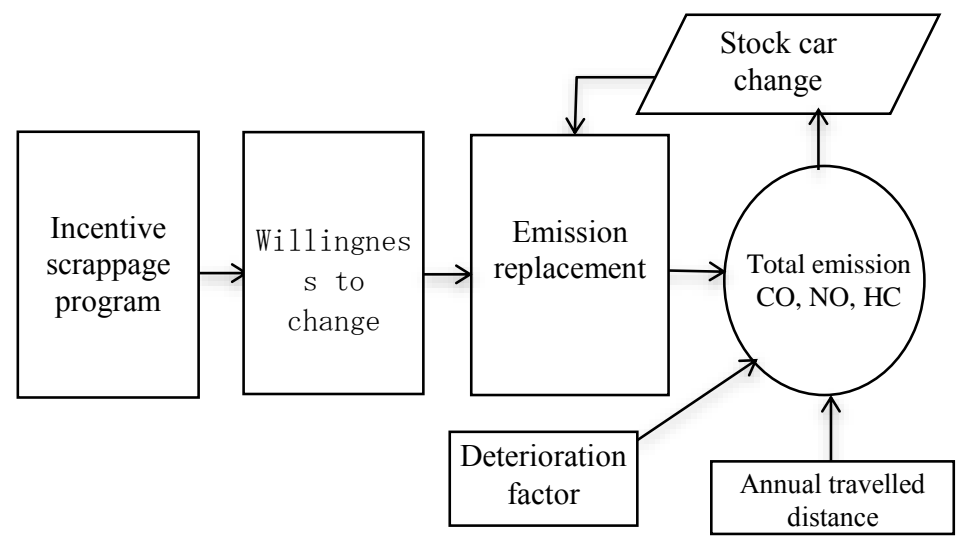

Figure 2: Research framework



Figure 3:Incentive program flow chart

Since we prepared the LCGC car as an option to replace the respondent's existing old car, we assumed that the car owner's income is in the segment of minimum annual income \$4,500 USD-\$10,000 USD. This segment is considered to be the group that can buy a new LCGC car with a 30\% down-payment of the average LCGC car price of \$9,500 USD. The annual interest rate was $12.42 \%$, with a 5 year loan. The final emissions (CO, NO, HC) after the incentive scrappage program has been implemented will be estimated. The deterioration factor and the annual travel distance obtained from the 120 respondents will be used to calculate the emissions.

\subsection{Willingness to change old non-euro car to LCGC car}

Measuring willingness to change was the approach used to estimate how the old car owners respond to the incentive program concerning the replacement. The respondents were questioned about their intention and willingness to change to a newer car with several reasons to choose from. From the beginning, we have presumed that voluntary car retirement is still very difficult to implement (zero incentive as compensation). Voluntary replacement occurs only if the environmental awareness of the individual is very high. We also offered several replacement reasons; better fuel consumption, smaller engine capacity, better exhaust gas emission conversion, and other reasons prior to offering the specific LCGC car. To assure us of the choice of the respondent, we also re-questioned them to cross-check to ensure that their choice was the most appropriate answer after an interview. All of the questionnaire procedures were guided using the flowchart in Figure 3. The screening started from the question confirming their car age. If the car's age was more than 24 years old, then we offered the incentive. The replacement was conducted after and if the owner decided that their chosen incentive option was 
to replace their old car with the LCGC car. Respondents who had no interest did not proceed to the next step. The reason for having no interest was varied. Respondents who owned a car that was younger than 24 years old showed their intention to participate in the program, so they were also considered as a contribution to the level of willingness. However, in the calculations, only the cars older than 24 years were targeted.

There were two factors that we considered to affect the willingness to express the probability of the owner replacing their old car. These were the probability of changing to the LCGC car P(A), and the probability of choosing the offered cash incentive $\mathrm{P}(\mathrm{B})$ respectively. WR is described as an independent correlation between two events, such as the probability of changing old non-euro cars to an LCGC car P (A), and the probability of choosing a cash incentive amount to replace their old non-euro car with an LCGC car P (B). If the two events are not influenced by one another, then the probability of both occurring is the product of the probabilities of each occurring separately. Independent correlation was considered because there is the probability of an old non-euro replacement with zero incentive or voluntary replacement. NER is the sum of the product between $\mathrm{P}$ (A) and P (B). Maximum probability 1 considers that $100 \%$ of old car owners will not replace their car, while minimum probability 0 assumes that all car owners will change their old car.

Hence, the willingness rate to change to the LCGC car with a certain amount of desired incentive can be described as:

$$
\begin{gathered}
W R=P(A \cap B)=P(A) \cdot P(B) \ldots(1) \\
N E R=\left(\sum_{t=24}^{N} N E\right) \cdot W R \ldots(2)
\end{gathered}
$$

$\begin{array}{ll}\text { WR } & \text { : Willingness rate of changing old non-euro car to the LCGC car } \\ \text { NER } & \text { : Number of non-euro cars with a car age more than } 24 \text { years replaced by the LCGC car (car unit) } \\ \text { NE } & \text { : Number of non-euro cars (car unit) } \\ \text { A } & \text { : Event of changing old non-euro cars with the LCGC cars } \\ \text { B } & \text { : Event of choosing the offered incentive to replace the old non-euro car with an LCGC car } \\ \text { P (A) } & \text { : Probability of changing the old non-euro car to an LCGC car } \\ \text { P (B) } & \text { : Probability of choosing the offered incentive to replace their old non-euro car to an LCGC car } \\ \text { N } & \text { : Number of targeted non-euro cars with a car age of more than } 24 \text { years (car unit) }\end{array}$

In the previous research, the willingness to change the targeted vehicle and the amount of incentive was not mentioned clearly. The policy of the stakeholder and annual budget planning become one of the triggers used to decide on the scheme of the incentive scrappage program. For example, German policy required new cars purchased as a replacement to have a minimum age of nine years in exchange for the car scrapped. This has led to an eligible pool of 17 million cars, or 41 percent of all cars registered in Germany. Moreover, under the German program, the car does not have to be brand new, but a car registered to another person for at most 14 months can also qualify for the governmental subsidy of 2,500 euros per vehicle. This incentive is only guaranteed to private car owners, and commercial entities are excluded from the program.

The scenario of the scrappage program also varies. The cash return incentive gives the incentive in the form of cash to the old car owner without the obligation to change to a certain car type, or with the condition to replace it with a designated car, as two examples. The amount of incentive also depends on the necessity and condition in each country. Determining the scenario for non-euro cars older than 24 years is also aimed at limiting the calculations involved and considering that the amount of scrappage incentive is limited by the stakeholder budget. We assume that all vehicles registered up to 2001 before the emission standard Euro 2 was implemented are non-euro cars, even though the possibility of euro cars also existing at this time cannot be neglected. However, the number will be less compared to the number of existing non-euro cars.

\subsection{Incentive scrappage program}

We constructed the scrappage program with a compensation incentive scenario in order to reduce the significant contribution of non-euro cars to air pollution. We set several options for the available incentives in the questionnaire's construction. The purpose is to discover the tendency of the respondents when they replace their old non-euro car with a LCGC car. We set \$0 USD, \$500 USD, \$1,000 USD, \$1500 USD, and \$2,000 USD as the cash options. This will reflect their replacement reason, be it because of their awareness of the environmental hazards or for financial reasons. This incentive is designed to stimulate the replacement as compensation for their actions. Setting the \$0 USD incentive was used to determine their awareness level, as \$0 USD is considered to be voluntary willingness. Car owners will replace their old car even without any incentive or compensation for the act. We also assume that if the awareness of the importance of 
the environment is high, then they will tend to replace their old car with a newer car even though no incentive is offered. The incentive introduction followed the Figure 3 flowchart. However, in this research, we have not included how the incentive budget will be absorbed and the source of the budget; it will be absorbed by the car price from the car manufacturer or intentionally from good will. The policy of the stakeholder was taken from the national budget.

\subsection{Estimation of stock car change after the incentive scrappage program was implemented}

The car stock changed after some of the non-euro cars were replaced with LCGC cars. Stock car change describes the changing of the old car and the new car in the context of the stock market. We can assume that all cars will be replaced with LCGC cars, and then individual old car retirement will be followed by new LCGC car registration. Car retirement due to natural disasters or traffic accidents were neglected in order to simplify the calculation. Stock cars (SC) will consist of the number of LCGC cars in the minimum annual income segment of \$4,500 USD-\$10,000 USD. This also details the car ownership model, the $30 \%$ down payment of the average LCGC car price of $\$ 9,500 \mathrm{USD}$, the annual interest rate of $12.42 \%$, and the 5 year loan formulation. Non-LCGC cars owned by individuals with a minimum annual income of more than $\$ 10,000$ USD will also be in the category of SC. From the incentive scrappage program, NAE will replace the replacement of non-euro car NERs. SC can be described as:

$$
S C=N A+N B+N A E+N E R
$$
$\mathrm{SC}$
NA
: Stock car (car unit)
NB
: Number of LCGC cars (car unit)
NER
: Number of non-LCGC cars (car unit)
NAE
: Number of non-euro cars with a car age of more than 24 years old replaced with an LCGC car (car unit) : Number of new LCGC registrations in relation to non-euro car replacement (car unit)

\subsection{Emission Factor (EF) and Deterioration Factor (DF)}

Euro 2 and non-euro cars have a big difference when it comes to the emission standard. Since non-euro cars are not equipped with a catalytic converter to convert its fuel and air combustion appropriately, gas residue will be emitted into the air without any compression and conversion. While Euro 2 cars have a lower emission standard, the degradation of the catalytic converter will cause the conversion capability to become worse after a certain travelled distance. As seen in Table 1, the emission standard of Euro 2 for $\mathrm{CO}$ is $2.2 \mathrm{gr} / \mathrm{km}$, which describes that $\mathrm{CO}$ gas will be considered as having emitted from the exhaust pipe of the vehicle if it measures 2.2 grams for each 1 kilometre of travel. NO and HC have a value of $0.05 \mathrm{gr} / \mathrm{km}$ and $0.45 \mathrm{gr} / \mathrm{km}$ respective, which assumes that $\mathrm{NO}$ and $\mathrm{HC}$ will be emitted measuring 0.05 grams and 0.45 grams per one kilometre of travelled distance (Nugroho and Fujiwara. 2005).

The amount of CO, NO, and HC increases by $60 \%$ from the initial emission level after exceeding 80.000 kilometres of travel (Boulter, 2009). We have named this degradation the deterioration factor (DF). High mileage vehicles will produce more air pollutants. The degradation is caused by a deterioration of the catalytic converter, related to the output of the exhaust pipe combustion. The deterioration of the catalyst is one factor that cannot be neglected (Borken-Kleefeld and Chen, 2015), therefore it should be considered in the calculation.

Table 1: Emission and deterioration factor for euro and non-euro cars

\begin{tabular}{ccccccc}
\hline \multirow{2}{*}{ Vehicle type } & $\begin{array}{c}\text { Emission } \\
\text { Standard }\end{array}$ & & CO & NO & HC & \multirow{2}{*}{ Deterioration factor } \\
\cline { 3 - 4 } Euro car (LCGC and non-LCGC) & Euro 2 & 2.20 & 0.05 & 0.45 & $\begin{array}{c}\text { After } 80,000 \text { kilometer travelled, } \\
60 \% \text { increase after } 80,000 \mathrm{~km}\end{array}$ \\
Non-euro car & Uncontrolled & 2.14 & 8.38 & 59.55 & - \\
\hline
\end{tabular}

\subsection{Emission replacement after the incentive scrappage program was implemented}

The replacement of NER with NAE will consequently change the emission conditions. NERs with higher potential emissions will be replaced by NAEs with better emission standards. It will also be considered as the elimination of the emissions from an individual old car replaced with the emissions from an LCGC car. The elimination will be derived from the difference between the retired and new car's emission level. This means that the elimination level cannot be zero, because new replacement cars also emit gas even though the level is much lower compared to the emission level of the old cars. 


$$
\begin{aligned}
& E=S C \cdot E F \cdot A T D \cdot D F \ldots(4) \\
& E=\left[(N A+N B+N A E) \cdot E F_{1}+N E R \cdot E F_{2}\right] \cdot A T D \cdot D F \ldots(5)
\end{aligned}
$$

$\mathrm{E}$

SC

ATD

$\mathrm{EF}_{1}$

$\mathrm{EF}_{2}$

$\mathrm{DF}$

NA

NB

NER

unit)

NAE
: Total emission (CO, HC, NO) after LCGC implementation (ton)

: Stock car (Car Unit)

: Annual travel distance $(\mathrm{km})$

: Emission factor for euro 2 standard $(\mathrm{gr} / \mathrm{km})$

: Emission factor for non-euro standard $(\mathrm{gr} / \mathrm{km})$

: Deterioration factor (60\% increase after 80,000 kilometres travelled)

: Number of LCGC cars (car unit)

: Number of non-LCGC cars (car unit)

: Number of non-euro cars with a car age of more than 24 years where replaced with a LCGC car (car

: Number of new LCGC registrations after non-euro car replacement (car unit)

We differentiated between the emission standards of euro cars $\left(\mathrm{EF}_{1}\right)$ and non-euro cars $\left(\mathrm{EF}_{2}\right)$. The big difference between both standards has been shown in Table 1 became one of the most important elements in this estimation. For ATD, an annual travel distance of 13,000 kilometres was obtained from the odometer.

\section{RESULTS AND DISCUSSION}

\subsection{Euro and non-euro emission level difference}

The individual emission level between euro and non-euro cars stands as an important factor for determining emission contribution. As shown in Table 1, for each ATD 1,000 kilometres travelled, the emission rate of the CO, NO, and HC values were plotted. For HC, the emission rate of the non-euro cars was more than 32 times bigger compared to the euro car. The NO gas contribution was more than 8 times bigger and the $\mathrm{CO}$ rate was more than 27 times bigger compared to the $\mathrm{CO}$ emission rate than that of the euro car. By accommodating equation (4) and the emission standard in Table 1, we have calculated the euro and non-euro emission contribution of each year from 2001 until 2010. Non-euro cars had a higher rate of emission compared to euro cars as shown in Figure 4 for CO, NO, and HC. Although the proportion of euro cars each year is increasing, the contribution from non-euro cars is still big and, thus, cannot be neglected. Although the portion of non-euro cars only contributed $24.0 \%$ from the total stock car between 2001 and 2010, it dominates more than $80 \%$ of the emission levels for each year. In addition, in 2010, NO from non-euro cars contributed 81.2\%, HC 94.1\% and CO 93.2\% respectively. The level of the emissions from the exhaust pipes also became higher, simultaneously increasing with the degradation of the catalytic converter which functionally inhibits the formation of exhaust gas emissions. The contribution from non-euro cars to the total annual emission level from gasoline passenger cars is significantly higher compared to euro cars. Each emission gas (CO, NO, HC) shows a big difference year by year.

To accommodate the emission level change caused by the car's increased age for Euro 2 cars, EF and DF was used in the calculation. The deterioration factor reflects the capability of the catalytic converter in the exhaust gas pipe to convert emission gases. For every $80,000 \mathrm{~km}$ travelled, the gas level will be 1.5 times bigger compared to the initial condition. This means that the emission amount differs correlating to an increase in age. An older car will potentially emit a bigger amount of emission gases compared to a younger car. 
(a)

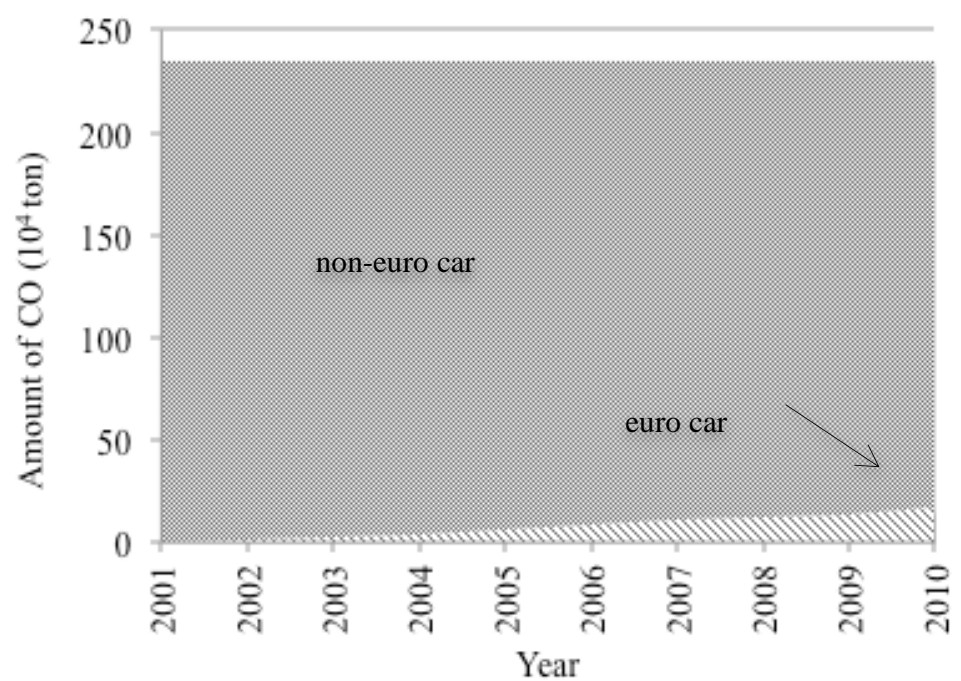

(b)

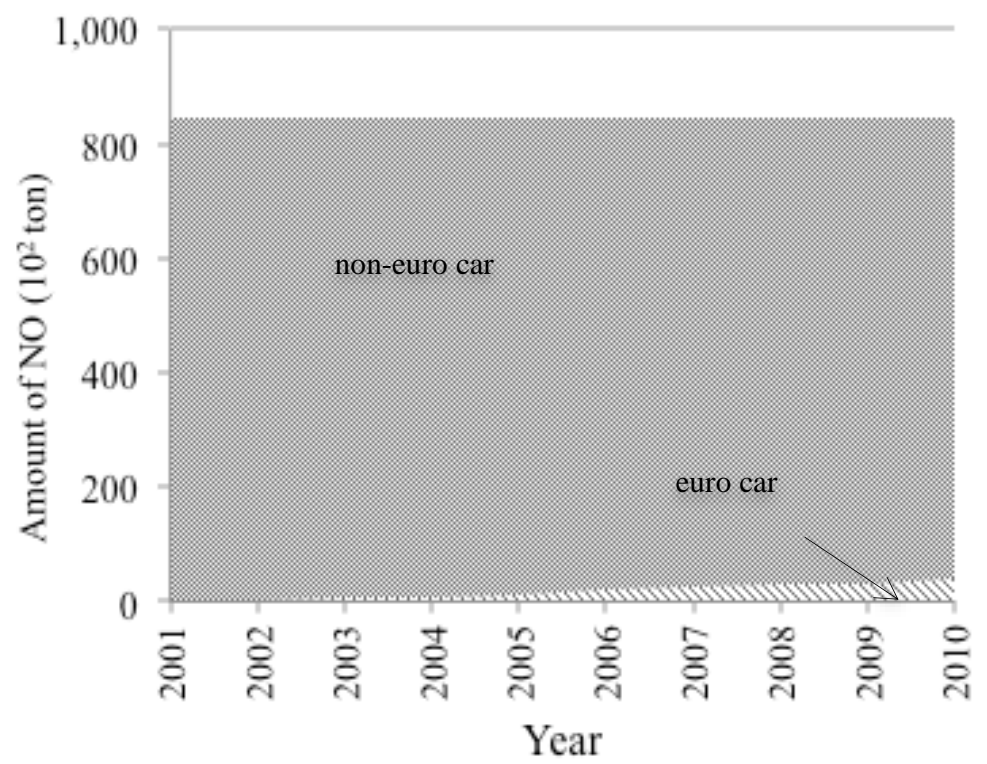

(c)

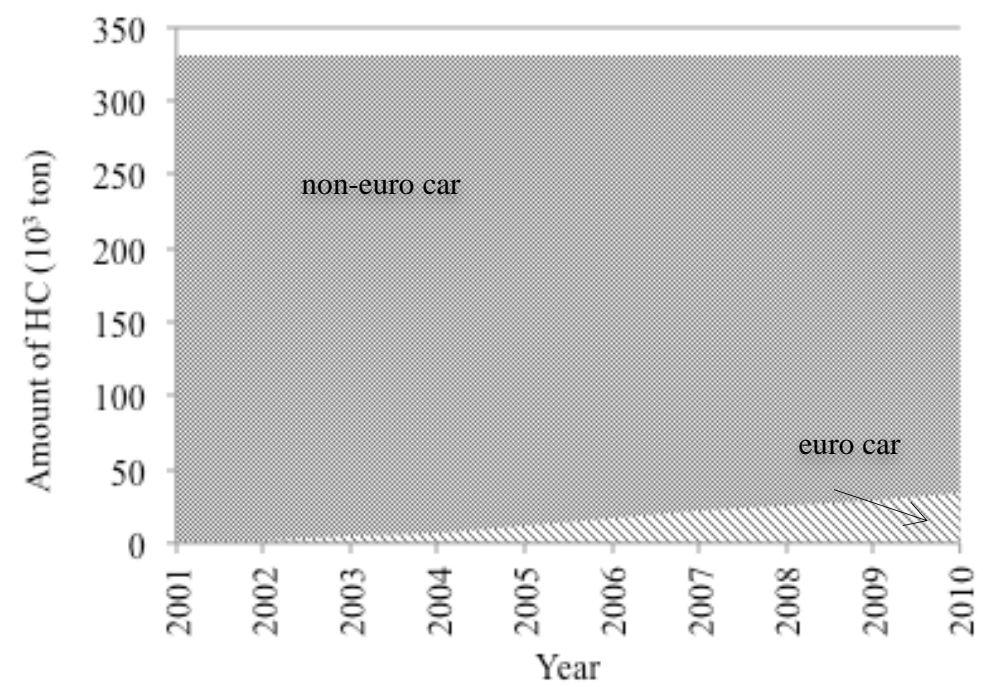

Figure 4: Estimated result of proportion of emission level for euro and non-euro until 2010 for(a) $\mathrm{CO}$, (b) $\mathrm{NO}$, (c) $\mathrm{HC}$ 


\subsection{Willingness to change the non-euro car to a LCGC car}

The probability of the owner of the old car changing to a newer LCGC car was confirmed through a survey of 120 respondents in Indonesia from the five big cities (Jakarta, Semarang, Surabaya, Medan, and Makassar). More than 70\% of the population is distributed within the five cities (BPS, 2013). Furthermore, more than $70 \%$ of car sales also occurs in these cities (Gaikindo, 2015). More than $82 \%$ of the respondents were willing to change their old car to an LCGC car with the maximum incentive value obtained being $\$ 2,000$ USD, with the latter totalling $78 \%$. This reflects that the financial aspect is still the most important factor when it comes to motivating the replacement compared to environmental awareness, which was also offered in the questionnaire. This was also supported by the questionnaire answer for voluntary retirement (zero incentive) being zero; none of the respondents chose the zero incentive option for non-euro car replacement.

By utilising equation (1), the willingness rate of changing old non-euro cars to an LCGC car (WR) can be obtained from the sum of the product between the probability of changing an old non-euro car to a LCGC car P (A) 70\% (0.7) and the probability of choosing an amount of offered incentive to replace the old non-euro car with the LCGC car P (B) $82 \%$ (0.82), calculated as follows:

$$
\begin{gathered}
W R=P(A \cap B)=P(A) \cdot P(B) \\
=(0.70) \cdot(0.82) \\
=0.574
\end{gathered}
$$

\subsection{Stock car change after the incentive scrappage program was implemented}

We have taken the starting point of the incentive program to be 2016, continuously introduced until the number of noneuro cars in lowest number in 2030, which is 20,628 units from the current non-euro stock of 3,038,913 units (in 2016). As long as scrappage regulations have not been implemented, we assume that all units still exist in the market including the remaining 20,628 units in 2030 .

The number of the non-euro cars gradually decreased by $78 \%$ from its original number. At the same time, the number of LCGC cars increased by the same number since the condition of the incentive program is to encourage change to the LCGC car. After being implemented in 2016, the portion of non-euro cars decreased drastically from $24 \%$ to $5 \%$ from the total stock. Consequently, the new LCGC registration for euro cars increased drastically in 2016. The peak graph in 2016 showed that the contribution of $78 \%$ of non-euro retirement was converted into euro cars. At the end of the calculations in 2030 , the number becomes $0.07 \%$. The decrease number will vary depending on the probability used in the calculation.

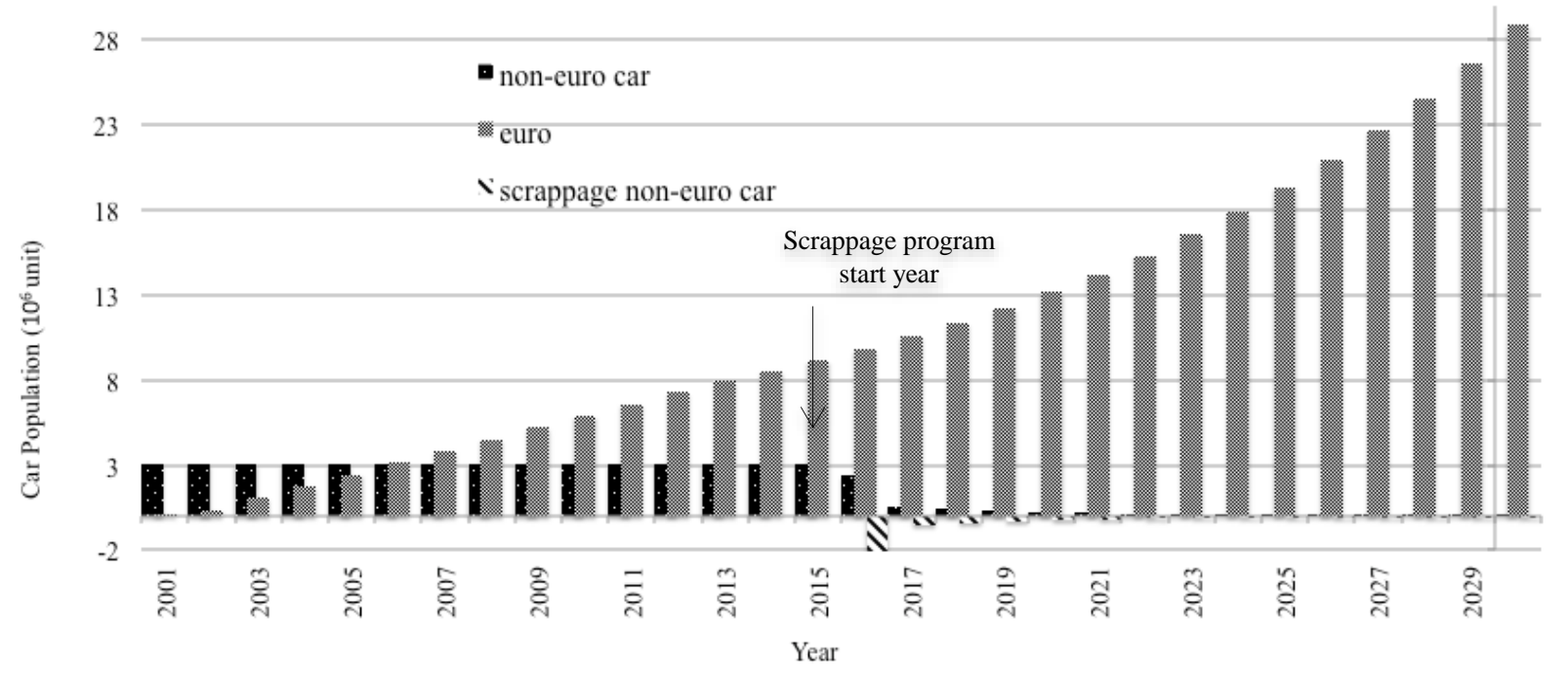

$\mathrm{Tl}$

Figure 5: Stock car change after incentive scrappage program implemented

compared to the population of euro cars in a certain year. The existing non-euro cars are constant until the implementation 
of the euro 1 standard regulation in Indonesia (Nugroho and Fujiwara, 2005). No particular regulation on the car's lifetime becomes the main reason that all non-euro cars were considered to still exist. It gradually decreased because of the retirement due to the incentive scrappage program introduced in 2016. The portion of non-euro cars will also vary depending on the duration of the scrappage incentive program. The minus portion of the scrappage non-euro car indicates the reduction of non-euro cars due to the non-euro car owners participating in the scrappage program. In this calculation, the duration is prolonged until the minimum value is reached at the end of the calculation in 2030 . The budget of the incentive will become a very important factor to reach this ideal condition. As long as the implementation period is long, the effect on the current change will be also significant. However, it is not an easy thing to implement when it comes to the actual condition, moreover when with a limited budget.

\subsection{Emission (CO, NO, HC) gas replacement after the incentive scrappage program is implemented}

We applied the simulation to estimate, utilising previous equation (5) above, to know the effectiveness of the incentive program in reducing the level of exhaust gas emissions, and how significant the elimination of the old car is on the emission level change (CO, NO, HC).

(a)

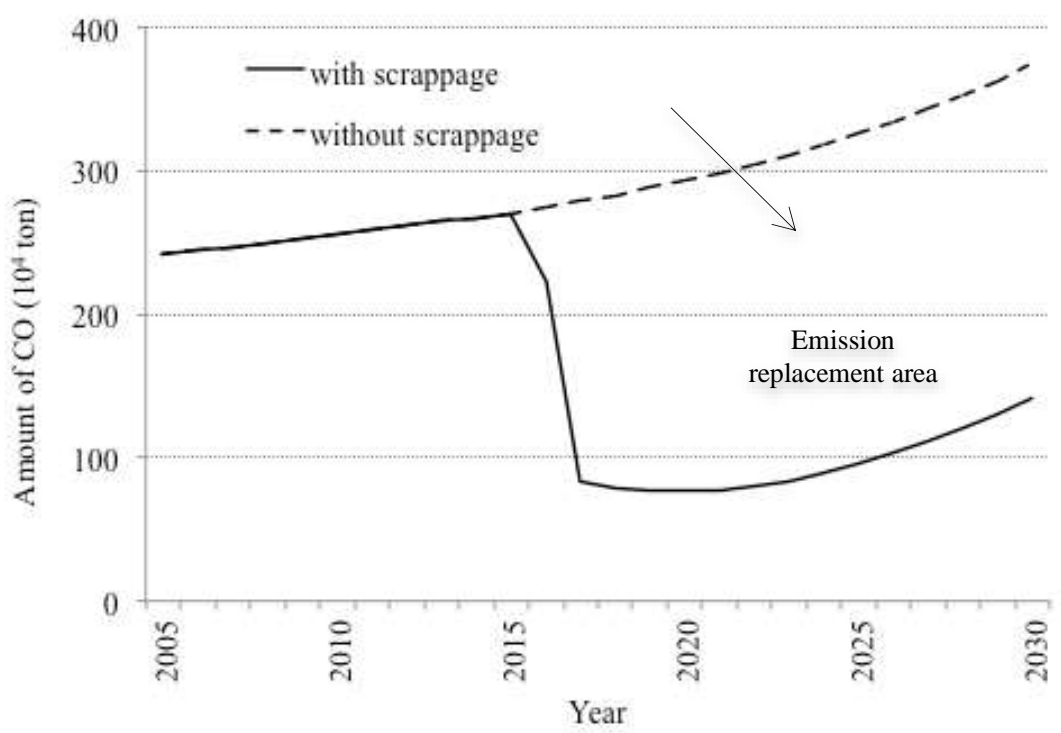

(b)




(c)

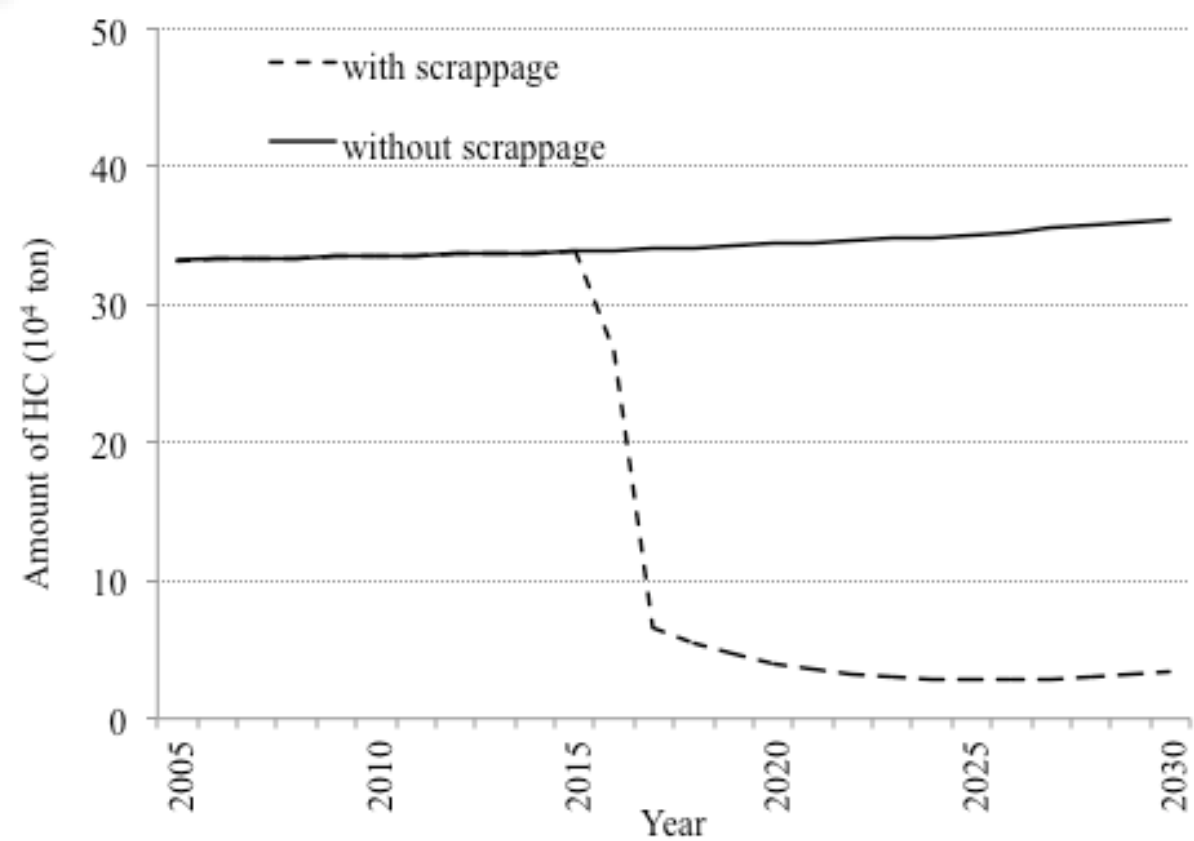

Figure 6: Emission level change for $\mathrm{CO}(\mathrm{a}), \mathrm{NO}(\mathrm{b})$, and $\mathrm{HC}(\mathrm{c})$

From the results shown in Figure 6, in general, each gas element (CO, NO, HC) decreased. The year 2016 became the initial reduced point because we applied the incentive scrappage program from 2016. This means that the retirement portion of non-euro cars will start to contribute to the decreasing of the emission level in 2016. For CO, it decreased significantly in 2016 by approximately $81.5 \%$ compared to the starting condition in 2016 . The total emission correlated with the scrappage program produced 1,777.6 million tons of $\mathrm{CO}$, which is significantly smaller compare to the situation without the scrappage program, which produced 2,178.7 million tons of CO. The gap between with scrappage program and without the incentive program constantly increased by around 3.2\%, approaching the 2016 condition (without the scrappage program). In the end 2030, the difference is $59.3 \%$ toward the $2016 \mathrm{CO}$ level, and more than half of the CO emissions can be reduced, from 3,065.0 million tons to 1,254.1 million tons. The constant increase was 3.2\% (56.2 million tons) for each year because one unit of scrappage non-euro cars should be replaced with newer LCGC cars. The significant reduction was predicted because of the individual emission level difference between euro cars and non-euro cars as described in Figure 5, which shows that non-euro cars have 27 times more emissions than euro cars.

NO also decreases drastically in the beginning of the implementation; it is $86.3 \%$ lower than the initial point in 2016 , from 105.8 million tons down to 91.4 million tons NO. The gap between with and without the scrappage program scenario has a $42.3 \%$ difference on average with the biggest gap occurring in 2019 at about $49.3 \%$. At the end of the simulation in 2030, the number of NO can be reduced by around 65.0 million tons or $68.1 \%$. The same tendency also happened for HC. In 2016, at $80.2 \%$, the $\mathrm{HC}$ level is lower than the initial condition around 296.8 million ton and reaches the end in 2030 $35.4 \%$ lower than without the scrappage program in the same year. Once the emission level decreases, it will slightly increase due to the number of LCGC car replacements also increasing. The tendency of the decrease of each gas follows the difference of the individual comparison as in Figure 4. The reduction portion also happens in the order of CO, HC, and NO. As seen in Figure 6 (a), (b), (c), we can conclude that the retirement of non-euro cars has a significant contribution to the reduction of the level of gas emissions from gasoline passenger cars.

\section{CONCLUSION}

Non-euro cars produce a significant emission contribution to the current level. Although its portion is only $24.0 \%$ out of the total stock (until the scrappage program was introduced), it provided a big contribution in 2010 (CO $81.2 \%$, $\mathrm{HC}$ 94.1\% and CO 93.2\%). The incentive scrappage program had a significant effect on changing the emission level. By utilising the willingness rate concerning the retirement of non-euro cars and offering LCGC replacements, there was a positive effect on emission reduction. For the emission gases, $\mathrm{CO}, \mathrm{NO}$, and $\mathrm{HC}$, the result showed a significance change compared to the scenario without the scrappage program. After the incentive program is implemented in 2016, the condition after 14 years in 2030 was that $\mathrm{CO}$ was reduced by $59.3 \%$, NO by $68.1 \%$, and HC by $35.4 \%$. The individual difference between euro and non-euro cars is one of the main reasons for this significant reduction. Therefore, we reached the 
conclusion that eliminating non-euro cars is one of the options to reducing the gas emission level in the case of gasoline passenger cars.

Increasing the participation rate will accelerate the level of reduction. There might need to be a bigger incentive to attract people to replace their old car. Extending the targeted type of car is one way to increase emission reduction. However, after the implementation of the scrappage program and when non-euro cars have been successfully eliminated, the trend of the emission rate showed an increase as described in Figure 6. This might be caused by the increase of LCGC cars on the road with owners with a minimum annual income of \$4,500 USD-\$10,000 USD. This annual income range previously could not buy car because of high price. Therefore, further study is still needed, focusing on the control of the increase in gas emissions.

A comprehensive control policy is necessary to maintain gas emissions from vehicles. As we understand that even euro car that are equipped with catalytic converters are also degrading, this might cause older vehicles to emit higher gas emissions in line with the extended travel distance. Controlling car age limit is one of the options to control the higher level of emissions from older vehicle.

\section{ACKNOWLEDGEMENT}

This work was supported as a special project in Tokai laboratory Osaka University. We would like to thank The Society for Risk Analysis (SRA) Asia for their support and advice during the International Conference in Taiwan, 21-23 August 2014 and the SRA International Conference 1-2 September 2016 in Osaka, Japan. We also would like to deliver our thanks to our colleagues, Dr. Kojima Naoya and Dr. Leticia Sarmento Dos Muchangos, for their fruitful discussions and valuable comments and advice. We thank The Proofers Team Professional Proofreading Services (www.proofers.co.uk) for editing a draft of this manuscript.

\section{REFERENCE}

[1] Alberini A, Harrington W, McConnell V. (1996). Estimating an emissions supply function from accelerated vehicle retirement programs. Rev Econ Stat, 78, 251-265. doi: 10.2307/2109927

[2] BenDor T, Ford A. (2006). Simulating a combination of feebates and scrappage incentives to reduce automobile emissions. Energy, 31, 1197-1214. doi: http://dx.doi.org/10.1016/j.energy.2005.05.024

[3] Böckers V, Heimeshoff U, Müller A. (2012). Pull-Forward Effects in the German Car Scrappage Scheme : A Time Series Approach.

[4] Borken-Kleefeld J, Chen Y. (2015). New emission deterioration rates for gasoline cars - Results from long-term measurements. Atmos Environ, 101, 58-64.

[5] Boulter PG. (2009). Emission factors 2009: Report 6 - deterioration factors and other modelling assumptions for road vehicles.

[6] BPS. (2013). Central Bureau of Statistics Report 2013. Central Bureau of Statistics Report: Number of Domestically Assembled Motor Vehicles (units), 2008-2013, https://www.bps.go.id/linkTabelStatis/view/id/1065.

[7] Gaikindo. (2015). Automotive Car Association Report: Domestic Auto Market \& Exim by Category 2015.

[8] Hennessy H, Richard SJT. (2011). The impact of government policy on private car ownership in ireland. Econ Soc Rev (Irel), 42,135-157.

[9] MOI. (2013). Decree of The Ministry Of Industry (MOI) No.33/M-IND/PER/7/2013.

[10] Nicholas Cet al (1999) Accelerating Vehicle Replacement and Environment Protection. J Transp Econ Policy 33:pp.329-42.

[11] Nugroho SB, Fujiwara A. (2005). Evaluating the Effects of a New Vehicle Emission Standard on Urban Air Quality in Jakarta City. J Int Dev Coop, 11, 17-37.

[12] Yamamoto T, Madre JL, Kitamura R. (2004). An analysis of the effects of French vehicle inspection program and grant for scrappage on household vehicle transaction. Transp Res Part B Methodol, 38, 905-926. doi: 10.1016/j.trb.2004.02.001 